\title{
Discovery, Characterization, and Pharmaceutical Applications of Two Loratadine-Oxalic Acid Cocrystals
}

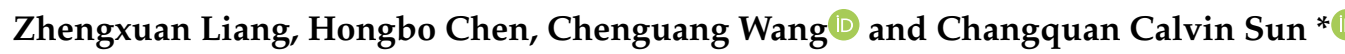 \\ Pharmaceutical Materials Science and Engineering Laboratory, Department of Pharmaceutics, \\ College of Pharmacy, University of Minnesota, Minneapolis, MN 55455, USA; liang650@umn.edu (Z.L.); \\ chen4515@umn.edu (H.C.); wang4889@umn.edu (C.W.) \\ * Correspondence: sunx0053@umn.edu; Tel.: +1-612-624-372; Fax: +1-612-626-212
}

Received: 21 October 2020; Accepted: 30 October 2020; Published: 3 November 2020

check for updates

\begin{abstract}
Loratadine (Lor) is an antihistamine drug commonly used to relieve the symptoms of allergy. It has high permeability but low solubility under physiological conditions. To overcome the problem of low solubility, we synthesized and characterized two Loratadine multi-component crystalline phases with oxalic acid (Oxa), i.e., a 1:1 Lor-Oxa conjugate acid-base (CAB) cocrystal (Lor-Oxa CAB) and a 2:1 Lor-Oxa cocrystal monohydrate (Lor-Oxa hydrate). Both cocrystals exhibited an enhanced solubility and intrinsic dissolution rate (IDR) compared to Lor and adequate physical stability. The intrinsic dissolution rate of Lor-Oxa CAB is 95 times that of Lor, which makes it a promising candidate for tablet formulation development.
\end{abstract}

Keywords: cocrystal; Loratadine; solubility; intrinsic dissolution rate; compression

\section{Introduction}

The low aqueous solubility of drugs is a major challenge to the design of oral dosage forms [1]. It may lead to poor drug bioavailability because of the slow dissolution process before drug molecules can be absorbed into the systemic circulation. Many approaches have been developed to enhance solubility and dissolution, including particle size reduction, cosolvents, surfactants, more soluble crystal forms, amorphous solid dispersions, cyclodextrins, solid lipid nanoparticles, and other colloidal drug-delivery systems [2]. Cocrystallization is a crystal engineering technique widely used in pharmaceutical research and the development of drugs [3,4]. It exploits non-covalent interactions between neutral or ionic components with a defined stoichiometry in a solid-state structure [5], which could improve the physicochemical properties of active pharmaceutical ingredients (API), including solid-state stability, such as sublimation tendency and hydration tendency [6,7], solubility [8] and dissolution [9], mechanical properties [10], permeability [11], and punch sticking propensity [12,13].

Loratadine (Lor) (Scheme 1a) is a second-generation tricyclic H1 antihistamine, used to treat itching, congestion, rhinorrhea, tearing, and sneezing by preventing and suppressing the response to histamine or allergen. Its non-sedating nature, due to the high peripheral selectivity and low ability to cross the blood-brain barrier, makes it a medicine of choice for treating allergies [14]. Lor is a weakly basic drug $\left(\mathrm{p} K_{\mathrm{a}}=5.25\right)$ [15], belonging to the Biopharmaceutical Classification System (BCS) Class II [16]. The solubility of Lor decreases exponentially with increasing $\mathrm{pH}$, which partially results in high variability in pharmacokinetic parameters $[16,17]$. The solubility of Lor in $\mathrm{pH} 6.8$ phosphate buffer is $0.7 \mathrm{mg} / \mathrm{L}$ [18]. Given the wide use of Lor, a new crystal form of Lor with improved solubility and dissolution rate, which may reduce variability in bioavailability, as well as enhanced powder properties for more efficient pharmaceutical processing, is desired for developing new Lor tablets 
with better in vivo performance [19]. Past efforts to improve the solubility of Lor include the use of complexes [20,21], solid dispersion [22,23], solid lipid microparticles [24], solid lipid nanoparticles [25], self microemulsifying particles [26], and coamorphous systems [27]. However, the cocrystallization or salt formation approach has so far been unsuccessful [28].

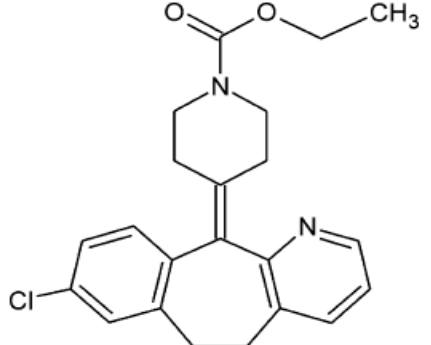

(a)<smiles>O=C(O)C(=O)O</smiles>

(b)

Scheme 1. Chemical structures of (a) Loratadine (molecular weight $(\mathrm{MW})=382.88 \mathrm{~g} / \mathrm{mol}$ ) and (b) oxalic acid (MW $=90.04 \mathrm{~g} / \mathrm{mol})$.

In this study, a series of organic acids, as potential coformers or salt formers, were attempted to screen for new multicomponent crystalline forms of Lor. Two new crystal form with oxalic acid (Oxa, Scheme 1b) were discovered, i.e., a Lor-Oxa conjugate acid-base salt (Lor-Oxa CAB) with the Lor to Oxa ratio of 1:1 and Lor-Oxa cocrystal monohydrate (Lor-Oxa hydrate, Lor:Oxa: $\mathrm{H}_{2} \mathrm{O}=2: 1: 1$ ). The pharmaceutical properties, including crystal structure, dissolution, thermal property, physical stability and mechanical property, of both new crystal forms were characterized. Their suitability for developing a tablet product with a faster and more robust drug-release performance and manufacturability was assessed.

\section{Materials and Methods}

\subsection{Materials}

Loratadine was purchased from Wuhan Biocar Bio-pharm Co. Ltd. (Wuhan, Hubei, China). Oxalic acid anhydrate (1.6\% water), malonic acid, benzoic acid, DL-malic acid, nicotinic acid, and succinic acid were purchased from Sigma-Aldrich (St. Louis, MO, USA). All materials were used as received. Microcrystalline cellulose (MCC; Pharmacel 102) was provided by DFE Pharma (Goch, Germany).

\subsection{Screen for New Solid Forms of Loratadine}

Two methods were used to screen for new solid forms of Lor. In one method, each candidate carboxylic acid (1 mmol) and Lor $(1 \mathrm{mmol})$ was suspended in $2 \mathrm{~mL}$ acetone with a magnetic stirring bar at $4{ }^{\circ} \mathrm{C}$ (carried out in a walk-in cold room) for $24 \mathrm{~h}$. Solids were filtered and characterized by powder X-ray diffraction (PXRD). In another method, $1 \mathrm{mmol}$ of each of Lor and a carboxylic acid were fully dissolved in $5 \mathrm{~mL}$ solvent in a $20 \mathrm{~mL}$ scintillation vial with heating. The vial was covered with parafilm with a few pin holes and left in a fume hood undisturbed to allow solvent to slowly evaporate. The resulting solids was characterized by PXRD.

\subsection{Single Crystal Preparation}

Equimolar Lor $(765.76 \mathrm{mg}, 2 \mathrm{mmol})$ and Oxa $(180.08 \mathrm{mg}, 2 \mathrm{mmol})$ or 2:1 molar ratio Lor $(765.76 \mathrm{mg}$, $2 \mathrm{mmol}$ ) and Oxa (90.04 mg, $1 \mathrm{mmol})$ were dissolved in $6 \mathrm{~mL}$ acetone. The vials were left in a cold room $\left(4^{\circ} \mathrm{C}\right)$, covered by parafilm with holes introduced to allow slow evaporation of the solvent and crystal growth. Crystals suitable for single crystal X-ray diffraction study were harvested within one week. Lor-Oxa CAB and Lor-Oxa hydrate were obtained from 1:1 and 2:1 samples, respectively. 


\subsection{Single Crystal X-ray Diffractometry (SCXRD)}

A Bruker-AXS Venture Photon-II diffractometer (Bruker AXS Inc., Madison, WI, USA), with a Photon-II (CMOS) detector, was used to collect the single crystal X-ray diffractometry (SCXRD) data at $100 \mathrm{~K}$ using Mo K $\alpha$ radiation (graphite monochromator). A suit of software, including APEX3, SADABS and SAINT, was used for data analysis. The structures were solved using SHELXT 2014 program and refined using a SHELXL 2018 program. Based on systematic absences and intensity statistics, the space group $\mathrm{P} 21 / \mathrm{c}$ was determined. A direct-methods solution was calculated, which provided most non-hydrogen atoms from the E-map. Full-matrix least-squares/difference Fourier cycles were performed to locate the remaining non-hydrogen atoms. All non-hydrogen atoms were refined with anisotropic displacement parameters. All hydrogen atoms were placed in ideal positions and refined as riding atoms with isotropic displacement parameters. Crystal structures were deposited at the Cambridge Crystal Database Centre (CCDC).

\subsection{Bulk Powder Preparation}

A batch of bulk powder of Lor-Oxa CAB was prepared by completely dissolving $4.59 \mathrm{~g}$ of Lor $(12 \mathrm{mmol})$ and $1.08 \mathrm{~g}$ of $\mathrm{Oxa}(12 \mathrm{mmol})$ in $15 \mathrm{~mL}$ acetone at room temperature. The solution was placed in a cold room $\left(4^{\circ} \mathrm{C}\right)$ with continuous stirring for $24 \mathrm{~h}$. The precipitant was then filtered, washed with acetone, and dried in a $35^{\circ} \mathrm{C}$ oven for overnight. A bulk powder of Lor-Oxa hydrate was prepared in a similar way, except $4.59 \mathrm{~g}$ of Lor $(12 \mathrm{mmol})$ and $0.54 \mathrm{~g}$ of Oxa $(6 \mathrm{mmol})$ was dissolved in $15 \mathrm{~mL}$ acetone with slight heating to obtain a clear solution before the sample was placed in the cold room.

\subsection{Powder X-ray Diffractometry (PXRD)}

Powder X-ray diffractograms were collected using a powder X-ray diffractometer (X'pert Pro; PANalytical, Westborough, MA, USA) equipped with $\mathrm{Cu}$ K $\alpha$ radiation (1.54059 Å). Samples were scanned between 5 to $30^{\circ} 2 \theta$ with a $0.02^{\circ}$ step size and a $1 \mathrm{~s} / \mathrm{step}$ dwell time at ambient temperature. The tube voltage and amperage were set at $45 \mathrm{kV}$ and $40 \mathrm{~mA}$, respectively.

\subsection{Thermal Analysis}

The thermal properties of powders were characterized by thermogravimetric analysis (TGA) and differential scanning calorimetry (DSC). TGA data were collected using a thermogravimetry analyzer (Model Q500, TA Instruments, New Castle, DE, USA). Powder samples (approximately $3 \mathrm{mg}$ ) were heated in open aluminum pans from room temperature to $300^{\circ} \mathrm{C}$ at $10^{\circ} \mathrm{C} / \mathrm{min}$ under $60 \mathrm{~mL} / \mathrm{min}$ dry nitrogen purge. DSC data were collected on a differential scanning calorimeter (Q1000, TA Instruments, New Castle, DE, USA). Powder samples ( $\sim 3 \mathrm{mg}$ ) were loaded into hermetically sealed aluminum Tzero pans and heated at a rate of $10{ }^{\circ} \mathrm{C} / \mathrm{min}$ from room temperature to $150^{\circ} \mathrm{C}$ under dry helium purge at a flow rate of $25 \mathrm{~mL} / \mathrm{min}$.

To assess the stability of Lor-Oxa hydrate, a powder sample was placed in a $100{ }^{\circ} \mathrm{C}$ oven. An aliquot of powder was taken out for PXRD analysis after 1, 2, 3, 4, 5, 6, 12, and 18 days.

\subsection{Hot-Stage Microscopy (HSM)}

Hot-stage microscopy (HSM) was performed with a polarized light microscope (PLM, Eclipse e200; Nikon, Tokyo, Japan). Images of crystals were captured by a DS Fi1 microscope digital camera. Crystals were heated to $150^{\circ} \mathrm{C}$ at the rate of $5{ }^{\circ} \mathrm{C} / \mathrm{min}$ with a temperature controller (Linksys 32; V.2.2.0, Linkam Scientific Instruments, Ltd., Waterfield, UK).

\subsection{Fourier Transformation Infrared Spectroscopy (FT-IR)}

Fourier transformation infrared spectroscopy (FT-IR) spectra (in the range of $4000-400 \mathrm{~cm}^{-1}$ ) of dry powders were obtained using a FT-IR spectrometer (NicoletiS50; Thermo Scientific, Waltham, MA, USA) equipped with a diamond attenuated total reflection (ATR) and DLaTGS detector. Each reported 
spectrum was an average of 32 scans of the same sample with a spectral resolution of $2 \mathrm{~cm}^{-1}$. Data processing was performed with the OMNIC 9.2 software.

\subsection{Moisture Sorption Isotherm}

Water sorption isotherms were collected using an automated vapor sorption analyzer (Intrinsic DVS, Surface Measurement Systems Ltd., Allentown, PA, USA) at $25^{\circ} \mathrm{C}$ with nitrogen flow rate of $50 \mathrm{~mL} / \mathrm{min}$. Sample weight was monitored by a micro balance. The Lor-Oxa CAB sample was first purged with dry nitrogen until a constant weight was obtained. The relative humidity $(\mathrm{RH})$ was varied from $0 \%$ to $95 \%$ during sorption with a step size of $5 \% \mathrm{RH}$. For Lor-oxa hydrate, the powder sample was exposed to a series of RHs from $95 \%$ to $0 \%$ with a step size of $5 \%$ RH. Samples were equilibrated at each step with the equilibration criteria of either $\mathrm{dm} / \mathrm{dt}=0.003 \%$ or maximum equilibration time of $6 \mathrm{~h}$ was reached before changing to the next target $\mathrm{RH}$.

\subsection{Solubility and Intrinsic Dissolution Rate (IDR)}

Solubility was determined by suspending an excess amount of a solid (100 mg) in $5 \mathrm{~mL}$ of pH 6.8 phosphate buffer under stirring at $25^{\circ} \mathrm{C}$ for $72 \mathrm{~h}$. Each suspension was passed through a $0.45 \mu \mathrm{m}$ Polytetrafluoroethylene (PTFE) membrane filter. The filtrate was appropriately diluted with the medium for measurement by a UV-vis fiber optic probe (Ocean Optics, Dunedin, FL, USA) at $250 \mathrm{~nm}$. Solution concentration was calculated based on a previously constructed calibration curve (Figure S1). The residual solids were collected and tested by PXRD to verify the solid phase.

Intrinsic dissolution rate (IDR) was determined by the rotating disc method $[29,30]$ in a phosphate buffer at $\mathrm{pH} 6.8$ to mimic duodenum $\mathrm{pH}$. For each sample, approximately $20 \mathrm{mg}$ of powder was compressed, using a custom-made stainless-steel die, at a force of $2000 \mathrm{lb}$ against a flat stainless-steel disc for $2 \mathrm{~min}$ to prepare a pellet $(6.39 \mathrm{~mm}$ in diameter). The surface of the pellet was visually smooth and coplanar with the die surface. While rotating at $200 \mathrm{rpm}$, the die was immersed in a $200 \mathrm{~mL}$ dissolution medium at $37^{\circ} \mathrm{C}$ in a water-jacketed beaker. An ultraviolet-visible (UV-vis) fiber optic probe (Ocean Optics, Dunedin, FL, USA) was used to continuously monitor the UV absorbance of the solution at $\lambda=250 \mathrm{~nm}$. IDR was calculated from the slope of the linear portion of the concentration-time profile and the pellet surface area exposed to the dissolution medium. PXRD of the pellet after IDR was collected to either confirm or eliminate the possibility of phase transition during dissolution.

\subsection{Tabletability}

Powder compaction was carried out using a universal material testing machine (model 1485; Zwick/ Roell, Ulm, Germany). To minimize the effect of particle size, powder samples were ground in a mortar with a pestle and passed through a $\# 60$ mesh $(\leq 250 \mu \mathrm{m})$ sieve before compaction. Particle sizes were assessed by PLM. Three mixtures containing $25 \%(w / w)$ of one of the three Lor crystal forms and $75 \%(w / w)$ of MCC PH102, were blended using a Turbula mixer (Glen Mills Inc., Clifton, NJ, USA) for $5 \mathrm{~min}$ at $49 \mathrm{rpm}$. Tablets were compacted under pressures ranging from 25 to $350 \mathrm{MPa}$ at a speed of $4 \mathrm{~mm} / \mathrm{min}$, using flat faced round punches ( $8 \mathrm{~mm}$ diameter). For pure crystal forms, the punch tip and die wall were lubricated with a suspension of magnesium stearate in ethanol $(5 \% w / v)$ and air dried prior to each compaction. For mixtures with MCC, no lubricant was used because of the low tendency of punch sticking and low ejection force. Tablets were relaxed for at least $24 \mathrm{~h}$ in a tightly closed glass vial before their dimensions were measured and broken down diametrically with a texture analyzer (TA-XT2i; Texture Technologies Corporation, Scarsdale, NY, USA). Tablet tensile strength $(\sigma)$ was calculated using Equation (1) [31]:

$$
\sigma=2 F /(\pi D h)
$$

where $F$ is the breaking force, $D$ is tablet diameter, and $h$ is tablet thickness. 
Powder true density was measured using a helium pycnometer (Quantachrome Instruments, Ultrapycnometer 1000e, Byonton Beach, FL, USA). Approximately $1 \mathrm{~g}$ of each powder was accurately weighed and placed into a sample cell (10 $\mathrm{mL}$ cell volume). The measurement was stopped when the coefficient of variation of the last five consecutive volume measurements was less than $0.005 \%$ or after 100 measurements, in which case the last five measurements were used. An average and standard deviation were calculated based on the five measurements. Tablet porosity $(\varepsilon)$ was calculated using Equation (2):

$$
\varepsilon=1-\rho / \rho_{\mathrm{t}}
$$

where $\rho$ and $\rho_{\mathrm{t}}$ are tablet density and powder true density, respectively.

\section{Results and Discussion}

\subsection{Crystal Screening and Structure Analysis}

Except for Oxa, no new crystal forms with other organic acids were observed during the initial screening efforts (Table S1). PXRD peaks different from the starting Lor and Oxa were obtained when Oxa (1:1 mole ratio) was used in slow evaporation from both acetone and ethyl acetate solutions, suggesting the presence of a new crystal form. Slow evaporation of an acetone solution of Lor and Oxa at 2:1 mole ratio led to another powder with a unique PXRD pattern, suggesting that at least two new solid forms of Lor and Oxa were obtained (Figure 1). Single crystal structures solved by SCXRD confirmed they are both new crystalline complexes between Lor and Oxa.

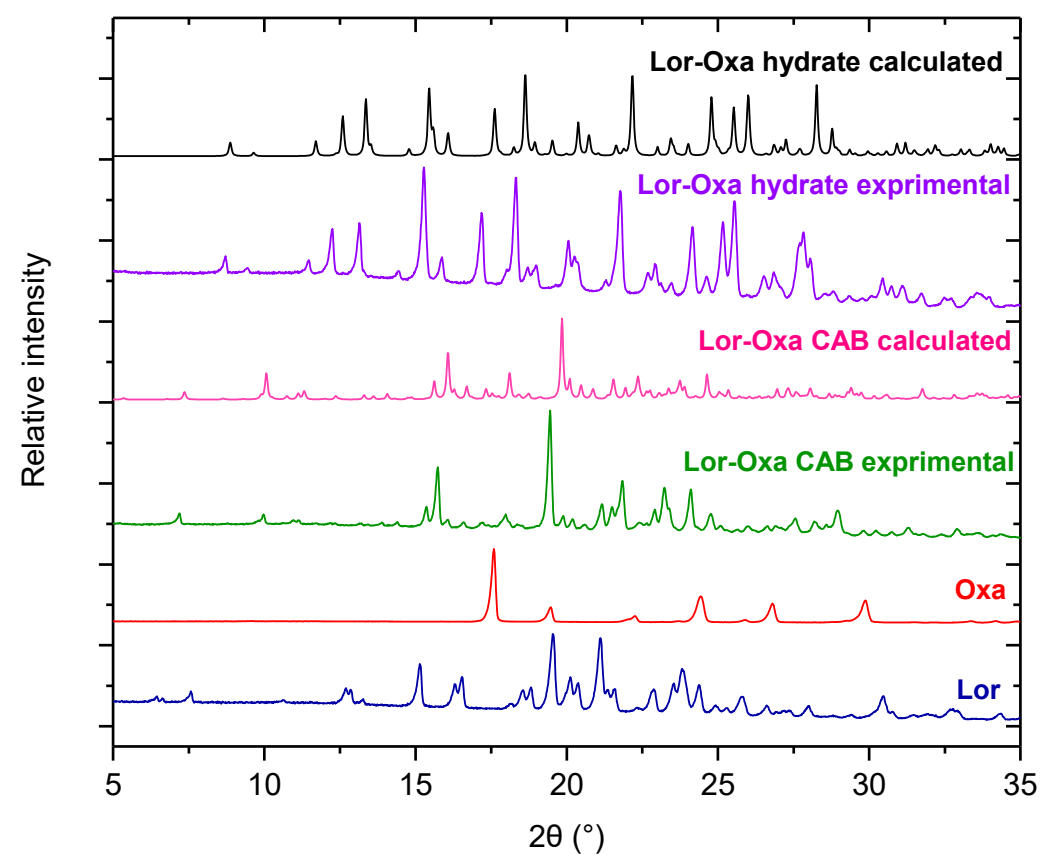

Figure 1. Experimental powder X-ray diffraction (PXRD) patterns of Lor, Oxa, Lor-Oxa conjugate acid-base salt (CAB), Lor-Oxa hydrate, and calculated PXRD patterns of Lor-Oxa CAB, and Lor-Oxa hydrate.

When crystallized from the 1:1 Lor:Oxa solution, the crystal belongs to the monoclinic $\mathrm{P} 2{ }_{1} / \mathrm{c}$ space group (Table 1). Its unit cell consists of six formula units $(Z=6)$ and each asymmetric unit contains 3 cationic Lor $^{+}, 1.5$ anionic Oxa-, and 1.5 neutral Oxa (Figure 2a). In this structure, 1D Oxa chains running along the $\mathrm{b}$ axis are formed via $\mathrm{O}-\mathrm{H} \cdots \mathrm{O}^{-}(2.510,2.512,2.515 \AA$ ) hydrogen bonds (Figure $2 \mathrm{~b})$. The Oxa chains are connected to surrounding Lor $^{+}$through $\mathrm{N}^{+}-\mathrm{H} \cdots \mathrm{O}=\mathrm{C}(2.624,2.726 \AA)$ and $\mathrm{N}^{+}-\mathrm{H} \cdots \mathrm{O}^{-}(2.897,2.988 \AA)$ to form a composite column (Figure 2c). The adjacent columns connect through $\pi \cdots \pi$ stacking $(3.439 \AA), \mathrm{Cl} \cdots \pi(3.320 \AA)$, and $\mathrm{C}=\mathrm{O} \cdots \mathrm{H}-\mathrm{C}(3.402 \AA)$ hydrogen bond to form a 
2D layer structure parallel to the (1 0 2) plane. The (102) layers stack to form a 3D packing structure, which is stabilized by weak $\mathrm{C}-\mathrm{H} \cdots \mathrm{O}(3.520 \AA$ ) hydrogen bonds between layers (Figure $2 \mathrm{~d}$ ).

Table 1. Crystallographic data for Lor-Oxa CAB and Lor-Oxa hydrate.

\begin{tabular}{ccc}
\hline & Lor-Oxa CAB & Lor-Oxa Hydrate \\
\hline Formula & $\mathrm{C}_{48} \mathrm{H}_{50} \mathrm{Cl}_{2} \mathrm{~N}_{4} \mathrm{O}_{12}$ & $\mathrm{C}_{23} \mathrm{H}_{26} \mathrm{ClN}_{2} \mathrm{O}_{5}$ \\
Formula weight & 945.82 & 445.91 \\
Temperature/K & 100 & 100 \\
Crystal system & Monoclinic & Monoclinic \\
Space group & $\mathrm{P} 2{ }_{1} / \mathrm{c}$ & $\mathrm{P} 2{ }_{1} / \mathrm{c}$ \\
$a, \AA$ & $16.5860(8)$ & $9.1806(3)$ \\
$b, \AA$ & $10.6133(5)$ & $11.4581(3)$ \\
c, $\AA$ & $38.1283(17)$ & $20.1427(6)$ \\
$\beta$, deg & $94.606(2)$ & $94.084(1)$ \\
Volume, $\AA^{3}$ & $6690.1(5)$ & $2113.48(11)$ \\
$\mathrm{z}$ & 6 & 4 \\
Dc/g.cm & 1.409 & 1.401 \\
$\mathrm{~F}(000)$ & 2976.0 & 940 \\
R1 [I $>2 \sigma(\mathrm{I})]$ & 0.0550 & 0.0552 \\
wR2 [I $>2 \mathrm{sigma}(\mathrm{I})]$ & 0.1291 & 0.1647 \\
CCDC & $1,840,642$ & $2,023,546$ \\
\hline
\end{tabular}

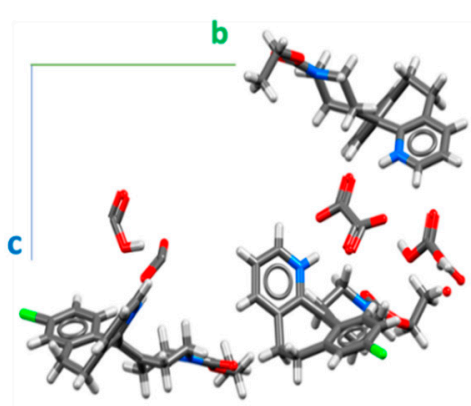

(a)

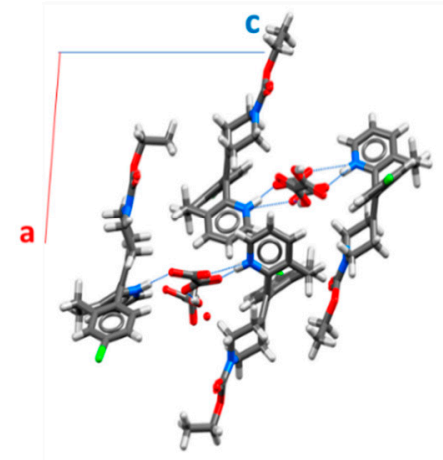

(c) b

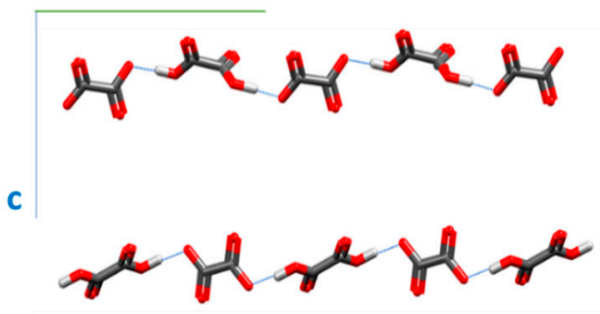

(b) $\left(\begin{array}{lll}1 & 0 & 2\end{array}\right)$

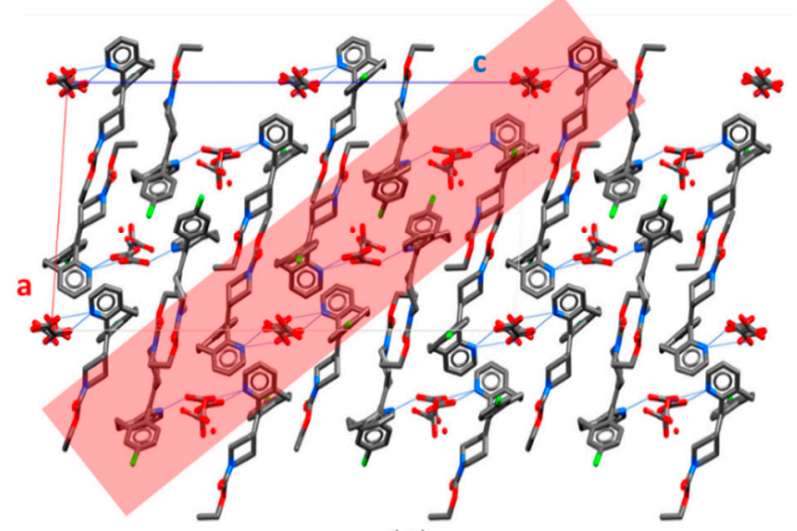

(d)

Figure 2. Crystal structure of Lor-Oxa CAB: (a) asymmetric unit; (b) oxalic acid chains; (c) composite column showing the interactions between an Oxa chain and surrounding Lor molecules (viewed into $b$ axis); (d) Crystal structure viewed into $b$ axis (hydrogens are omitted for clarity).

When crystallized from the 2:1 Lor:Oxa solution, the solid form also belongs to the monoclinic P21/c space group (Table 1). Its unit cell contains 4 formula units $(Z=4)$ and the asymmetric unit comprises 1 Lor, 0.5 Oxa (Oxa has an axis of symmetry), and one water molecule (Figure 3a). Lor and water interact via $\mathrm{C}=\mathrm{O} \cdots \mathrm{H}-\mathrm{O}(2.977 \AA)$ and $\mathrm{O}-\mathrm{H} \cdots \mathrm{Cl}(3.232 \AA)$ hydrogen bonds to form $1 \mathrm{D}$ chains 
(Figure 3b). One Oxa molecule further connects to two Lor molecules in adjacent chains via $\mathrm{O}-\mathrm{H} \cdots \mathrm{N}$ $(2.609 \AA), \mathrm{C}-\mathrm{H} \cdots \mathrm{O}=\mathrm{C}(3.322 \AA), \mathrm{C} \cdots \mathrm{H}-\mathrm{O}(3.448 \AA, 3.528 \AA)$ hydrogen bonds (Figure 3c) to form 2D zig-zagged layers. Finally, the layers stack to form a $3 \mathrm{D}$ packing structure (Figure $3 \mathrm{~d}$ ).
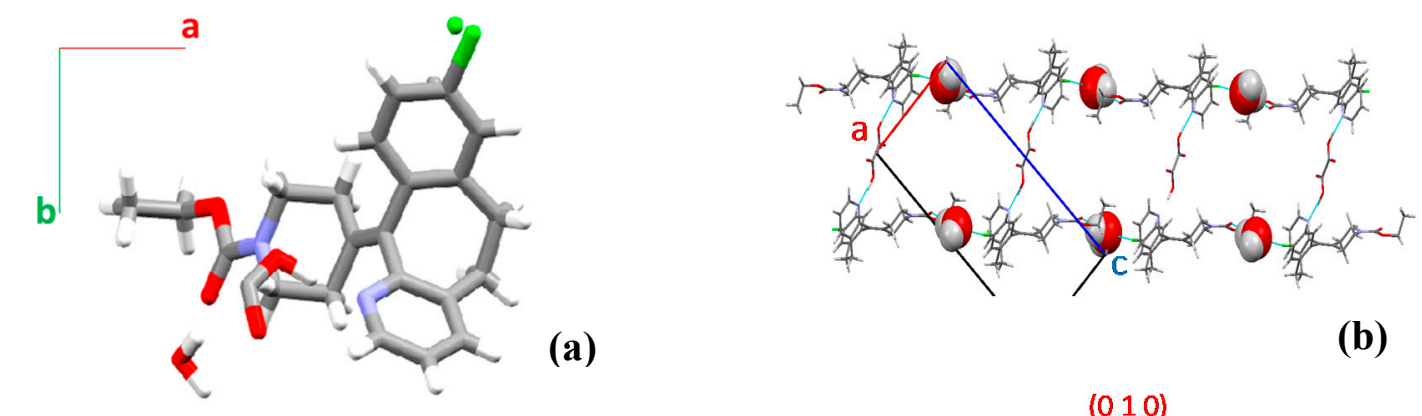

(a)

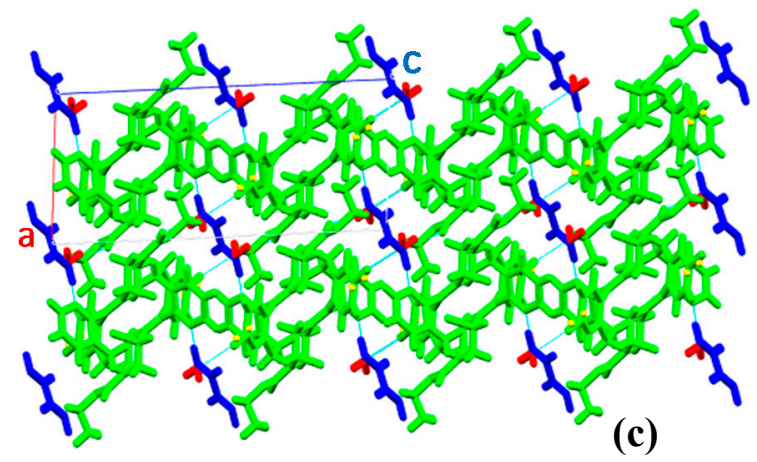

(b)

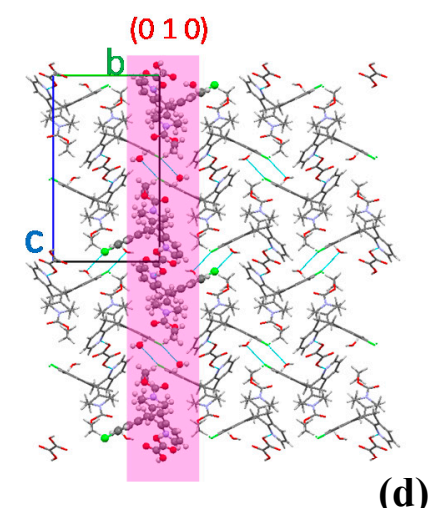

(d)

Figure 3. Crystal structure of Lor-Oxa hydrate: (a) asymmetric unit; (b) Lor-water chains bonded via Oxa; (c) structure of the (010) layer (Lor is green, Oxa is blue, and water is red), and (d) viewed into a-axis with a (010) layer is highlighted in pink.

The calculated PXRD patterns of the two new solid forms matched well with the PXRD patterns of the solids obtained from the slurry method (Figure 1), confirming the phase identity of these powders. For both solid forms, the systematic peak shift to the lower two theta angles in the experimental PXRD patterns compared to corresponding calculated patterns is attributed to the thermal expansion of crystal lattice. The crystal structures used for calculating PXRD were solved at $100 \mathrm{~K}$, which is substantially lower than room temperature. The smaller $\mathrm{d}$-spacing for each corresponding Miller plane $(\mathrm{h}, \mathrm{k}, \mathrm{l})$ at $100 \mathrm{~K}$ necessarily leads to a higher two theta angel.

\subsection{Formation Conditions of the Two Crystals}

Given that Lor-Oxa CAB was obtained at 1:1 Lor to Oxa ratio, and Lor-Oxa hydrate was prepared at 2:1 ratio, the amount of Oxa clearly plays a role in phase stability of both crystals. We experimentally examined this by identifying solid phases prepared by suspending Lor and Oxa at different ratios in acetone at $4{ }^{\circ} \mathrm{C}$. Phase identification was achieved by PXRD, using the $2 \theta$ of characteristic peaks for various solid forms: $7.52^{\circ}$ and $12.87^{\circ}$ for Lor, $10.04^{\circ}$ for Lor-Oxa CAB, and $8.87^{\circ}$ for Lor-Oxa hydrate (Figure 4, all ratios in Figure S2). At the 1:0.2 ratio, the product was a mixture of Lor and Lor-Oxa hydrate. At ratios from 1:0.3 to 1:0.5, pure Lor-Oxa hydrate was obtained. At ratios from 1:0.6 to 1:0.9, the powders were mixtures of Lor-Oxa hydrate and Lor-Oxa CAB, where the amount of Lor-Oxa CAB increased with increasing Oxa amount. When the Lor to Oxa ratio reached 1:1, the product was pure Lor-Oxa CAB. 


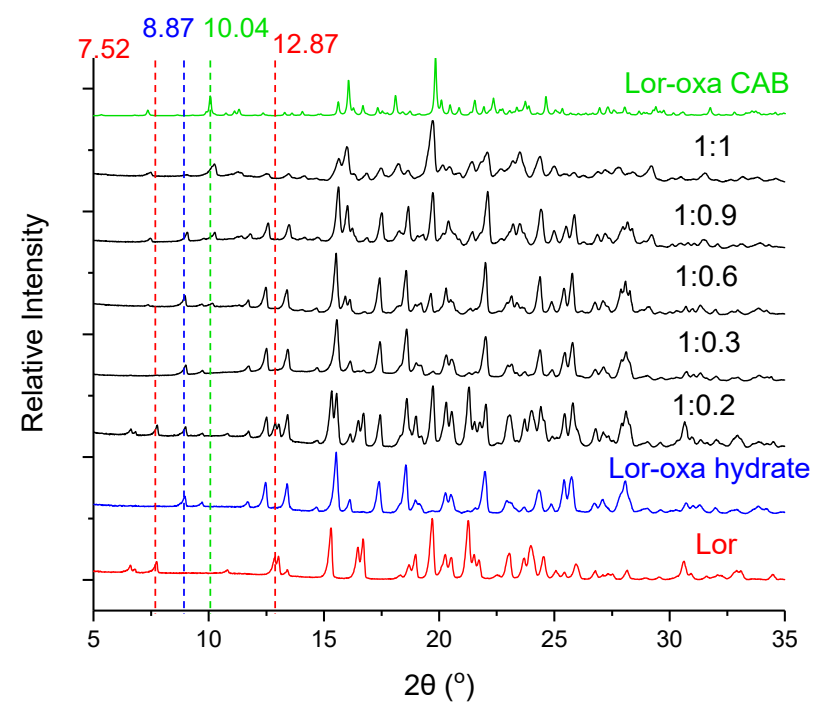

Figure 4. Effects of Oxa amount on phase change during slurry experiments. Lor to Oxa ratios are given.

\subsection{Solid State Characterization}

The TGA profile of Lor-Oxa CAB (Figure 5a) showed negligible weight loss below $150{ }^{\circ} \mathrm{C}$, suggesting acceptable thermal stability. This is important for further tablet development, which may involve drying [32]. Significant weight loss was observed at $\geq 150{ }^{\circ} \mathrm{C}$, likely due to the evaporation of Oxa from the melt. The DSC thermogram of Lor-Oxa CAB exhibited a single endotherm with an onset temperature of $124.29^{\circ} \mathrm{C}\left(\Delta \mathrm{H}_{\mathrm{f}}=69.78 \mathrm{~J} / \mathrm{g}\right)$ and peak temperature of $129.72{ }^{\circ} \mathrm{C}$ (Figure $5 \mathrm{~b}$ ). A Lor-Oxa $\mathrm{CAB}$ single crystal melted at $135^{\circ} \mathrm{C}$ in a HSM study (Figure $5 \mathrm{c}$, Video S1). The higher melting point observed during HSM experiment than that by DSC is attributed to the thermal lag during the HSM experiment due to poorer contact between the crystal and the glass slide.

(a)
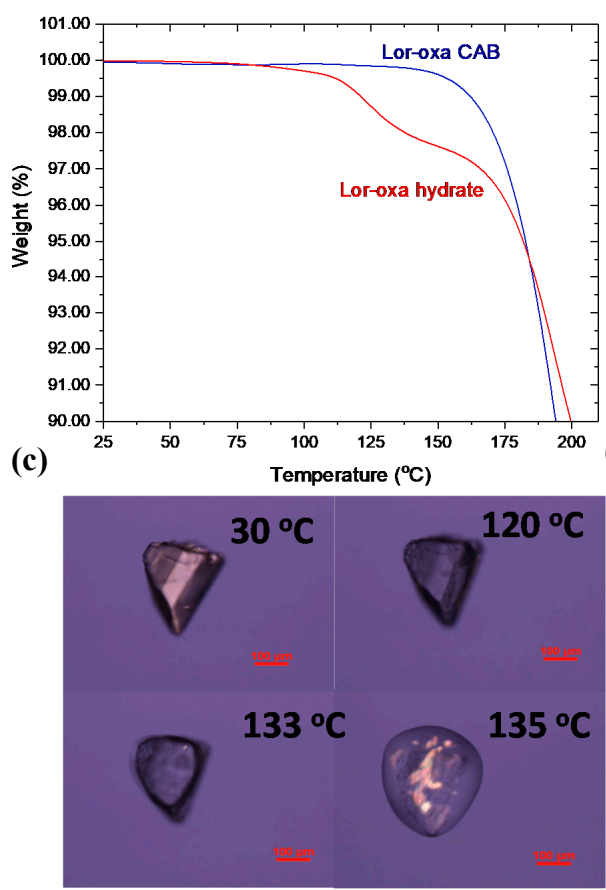

(b)
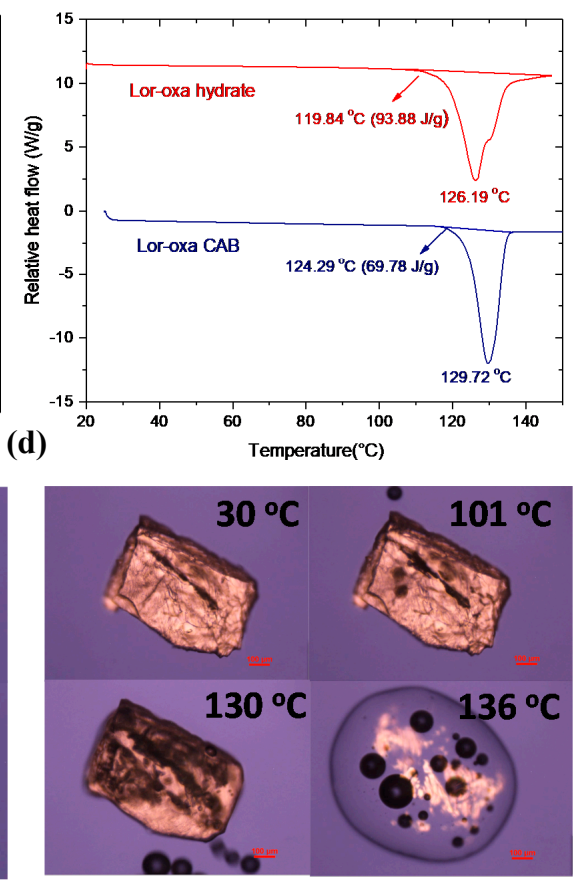

Figure 5. Thermal analyses of Lor-Oxa CAB and Lor-Oxa hydrate: (a) thermogravimetric analysis (TGA), (b) differential scanning calorimetry (DSC), (c) hot-stage microscopy (HSM) snapshots of Lor-Oxa CAB, and (d) HSM snapshots of Lor-Oxa hydrate. 
The weight loss of Lor-Oxa hydrate corresponding to dehydration initiates at around $92{ }^{\circ} \mathrm{C}$ and proceeds slowly until the accelerated weight loss at $\geq 112{ }^{\circ} \mathrm{C}$ (Figure 5a). The DSC thermogram of Lor-Oxa hydrate exhibited two overlapping endotherms with onset temperature of $119.84{ }^{\circ} \mathrm{C}$ $\left(\Delta \mathrm{H}_{\mathrm{f}}=93.88 \mathrm{~J} / \mathrm{g}\right)$ (Figure $\left.5 \mathrm{~b}\right)$. The onset temperature of the DSC endotherm is $\sim 28^{\circ} \mathrm{C}$ higher than the temperature corresponding to the initial weight loss observed on TGA. This temperature difference is larger than expected, which may be partially resulting from the depression of the dehydration reaction by the build up of water vapor from the initial dehydration in DSC pan. A Lor-Oxa single crystal released water bubbles when heated to $101{ }^{\circ} \mathrm{C}$ in an HSM experiment and continued through the melting of the crystal in the temperature range of $130-136{ }^{\circ} \mathrm{C}$ (Figure $5 \mathrm{~d}$, Video S2). This is consistent with the significant overlap of the two endotherms observed in the DSC thermogram of Lor-Oxa hydrate (Figure 5b).

The FT-IR spectra of Lor, Oxa, and the two new Lor cocrystals show distinct peaks (Figure 6). The strongest sharp absorption band at $1698 \mathrm{~cm}^{-1}$ of the Lor is attributed to the $\mathrm{C}=\mathrm{O}$ of the ester group, which is distinct from the broad $\mathrm{C}=\mathrm{O}$ absorption bands of the two carboxylic acid groups with a peak position at $1668 \mathrm{~cm}^{-1}$. The larger red-shift of Lor-Oxa hydrate $\left(26 \mathrm{~cm}^{-1}\right)$ than Lor-Oxa $\mathrm{CAB}\left(9 \mathrm{~cm}^{-1}\right)$ of the $\mathrm{C}=\mathrm{O}$ peak can be explained by the $\mathrm{O}-\mathrm{H} \cdots \mathrm{O}(2.977 \AA)$ hydrogen bond formation between ester $\mathrm{C}=\mathrm{O}$ and water. The $\geq 100 \mathrm{~cm}^{-1}$ red-shift of the $\mathrm{C}=\mathrm{O}$ absorption band of a fully deprotonated carboxylate group [33] was not obvious in the FT-IR spectra of both Lor-Oxa hydrate and Lor-Oxa $\mathrm{CAB}$ because of the overlapping of the much stronger $\mathrm{C}=\mathrm{O}$ absorption bands of Lor. The low intensity of $\mathrm{O}-\mathrm{H}$ absorption bands of Oxa in Lor-Oxa CAB is attributed to its participation in strong charge-assisted hydrogen bonds of $\mathrm{O}-\mathrm{H}_{\cdots} \cdots \mathrm{O}^{-}(2.510,2.512,2.515 \AA)$ and absence of water. In contrast, the hydroxyl groups of water and Oxa in Lor-Oxa hydrate only participate in weak hydrogen bonds $(\mathrm{O}-\mathrm{H} \cdots \mathrm{O}, 2.977 \AA$; $\mathrm{O}-\mathrm{H} \cdots \mathrm{Cl}, 3.232 \AA$ ) and, hence, exhibit higher intensity.

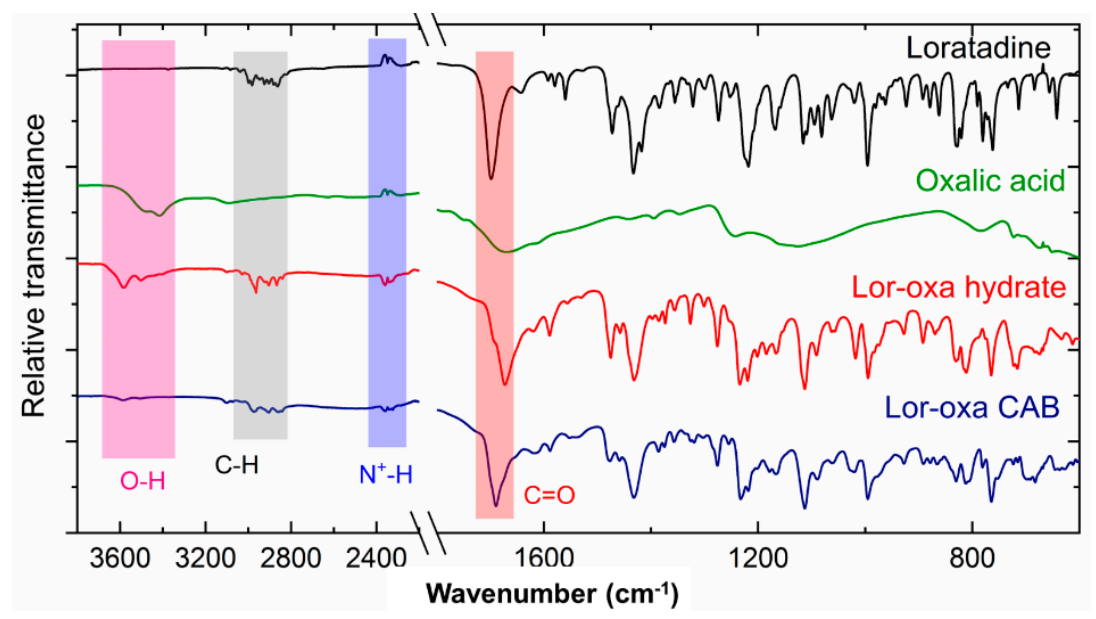

Figure 6. Fourier transform infrared (FT-IR) spectra of Lor, Oxa, Lor-Oxa CAB, and Lor-Oxa hydrate.

\subsection{Moisture Sorption and Desorption Behavior}

Both Lor-Oxa CAB and Lor-Oxa hydrate gained less than 1\% weight up to 95\% RH (Figure 7) and only slight hysteresis between sorption and desorption curves was observed (data not shown). The weight change was smooth not in a step-wise fashion. Therefore, the weight increase of both samples is due to the surface adsorption of moisture. The physical stability of Lor-Oxa hydrate against changes in RH is consistent with the TGA data (Figure 5a), which suggests that dehydration did not occur under dry nitrogen purge until temperature was at least $92{ }^{\circ} \mathrm{C}$. When stored in a $100{ }^{\circ} \mathrm{C}$ oven, Lor-Oxa hydrate did not undergo detectable dehydration after 1 day base on PXRD (Figure 8, longer time data is given in Figure S3). Characteristic peaks of Lor, e.g., $12.7^{\circ} 2 \theta$, appeared after two days. However, an appreciable amount of Lor-Oxa hydrate remained even after 6 days. Complete conversion from Lor-Oxa hydrate to Lor took about 12 days. The good stability of Lor-Oxa 
hydrate is attributed to the stabilization of water in the crystal structure by forming $\mathrm{C}=\mathrm{O} \cdots \mathrm{H}-\mathrm{O}$ $(2.977 \AA)$ and $\mathrm{O}-\mathrm{H} \cdots \mathrm{Cl}(3.232 \AA)$ hydrogen bonds. It suggests that Lor-Oxa hydrate could be used under conditions typically encountered during pharmaceutical manufacturing and storage without a high risk of phase change.

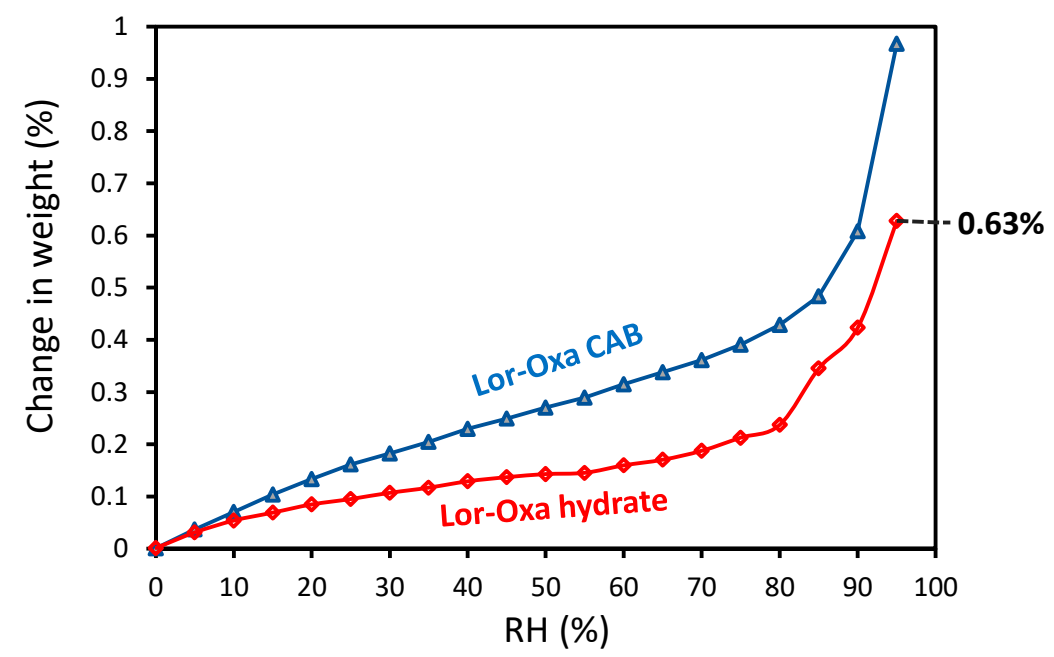

Figure 7. Moisture sorption isotherms of Lor-Oxa CAB and Lor-Oxa hydrate.

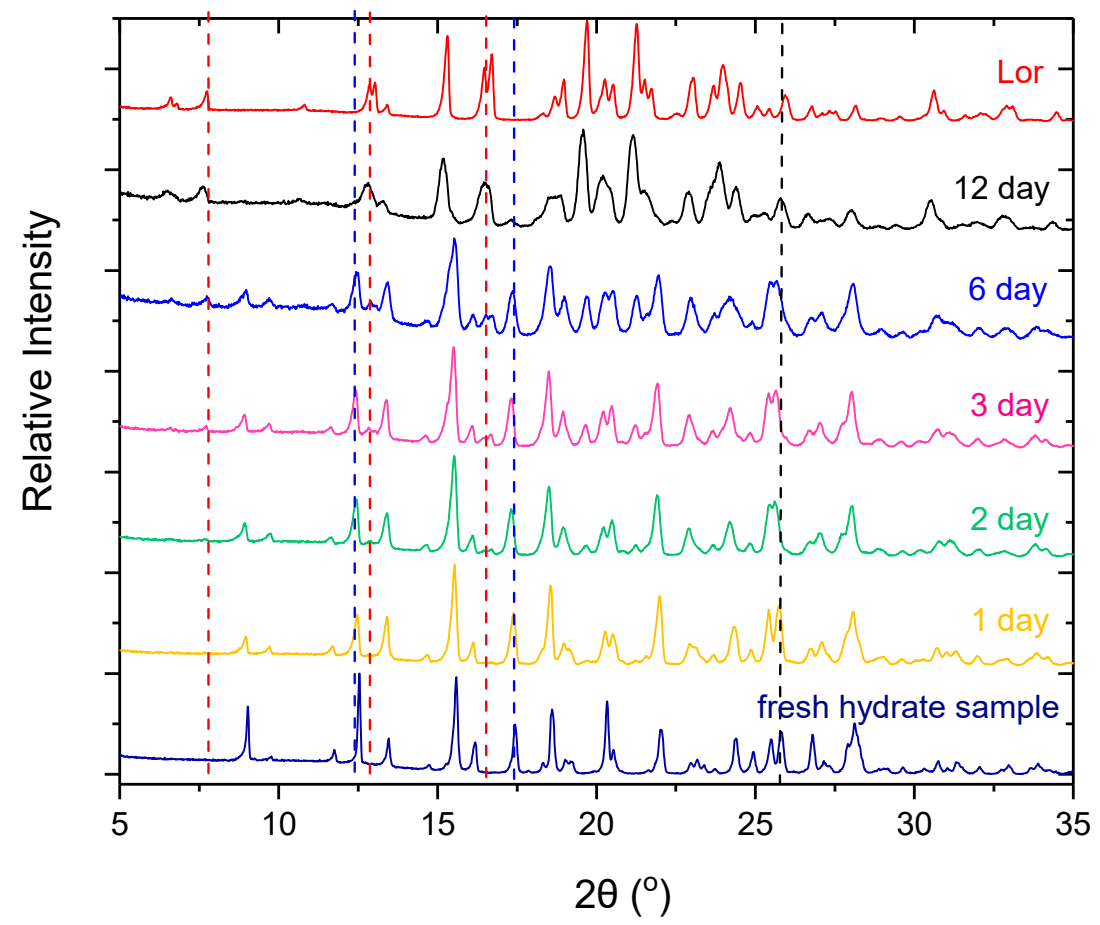

Figure 8. PXRD patterns of Lor-Oxa hydrate powder stored at $100{ }^{\circ} \mathrm{C}$.

\subsection{Solubility and Intrinsic Dissolution Rate}

Both solubilities and dissolution rates of the two new crystal forms of Lor are determined in $\mathrm{pH} 6.8$ phosphate buffer to mimic the human physiological environment. During solubility measurement at $25^{\circ} \mathrm{C}$, Lor-Oxa CAB converted to Lor-Oxa hydrate within three days while Lor-Oxa hydrate remained stable (Figure $\mathrm{S} 4$ ). The phase change suggests that Lor-Oxa CAB is more soluble than Lor-Oxa hydrate in the $\mathrm{pH} 6.8$ buffer [34].

Compared to Lor, Lor-Oxa hydrate displays both improved solubility (1.46 fold) and intrinsic dissolution rate (1.85 fold) (Figure 9a,b, Table 2). Lor-Oxa CAB exhibits a much higher IDR, 
about 95 times of Lor. In the IDR curve of Lor-Oxa CAB, the concentration of Lor in the medium initially increased linearly up to a concentration of $11.36 \pm 0.37 \mu \mathrm{g} / \mathrm{mL}$ and then decreased (Figure S5). The PXRD pattern of the Lor-Oxa CAB pellet after the IDR experiment matched that of Lor-Oxa hydrate, indicating conversion to Lor-Oxa hydrate (Figure 9c). The decline in the concentration of Lor after 10 min suggests bulk precipitation, which explains the observed turbidity of the dissolution medium (Figure 9d). Since the degree of supersaturation is the highest at the surface of pellet, free drug tends to precipitate out more easily at the pellet surface than in the bulk. Thus, Lor-Oxa CAB is a good model compound to study the bulk precipitation phenomenon. Potential reasons for bulk precipitation include: (a) the high dissolution rate leads to faster receding of the pellet surface than the time required to form nuclei on the pellet surface; and (b) the $\mathrm{pH}$ in the diffusion layer is lower than that in the bulk medium, which leads to a lower degree of supersaturation of Lor since the solubility of Lor is higher at a lower $\mathrm{pH}$.

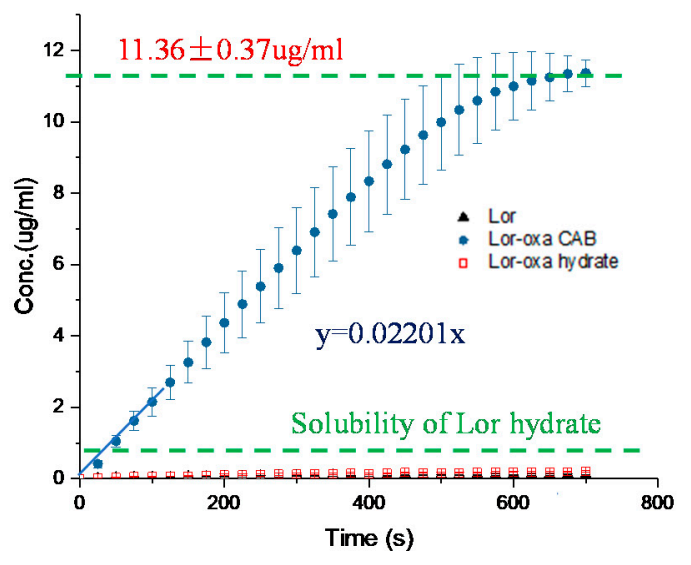

(a)

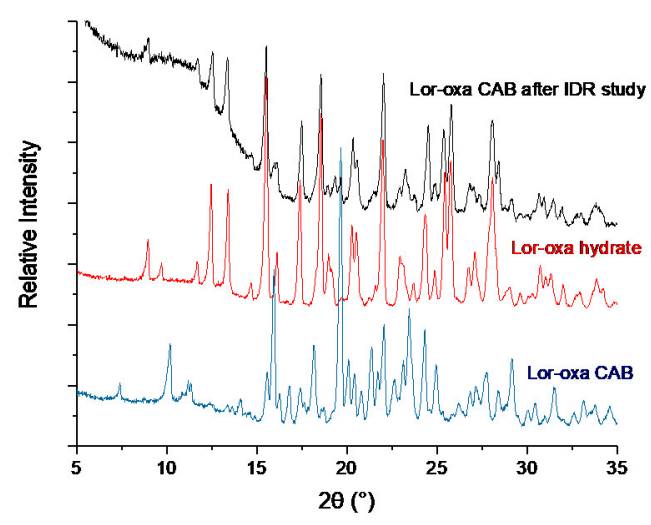

(c)

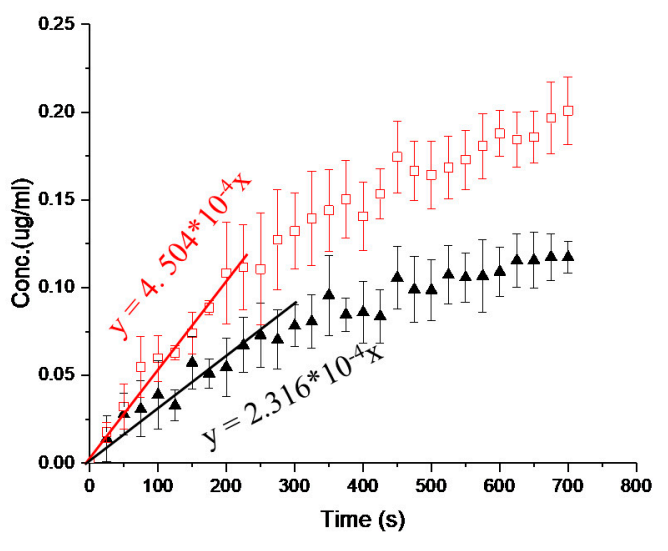

(b)

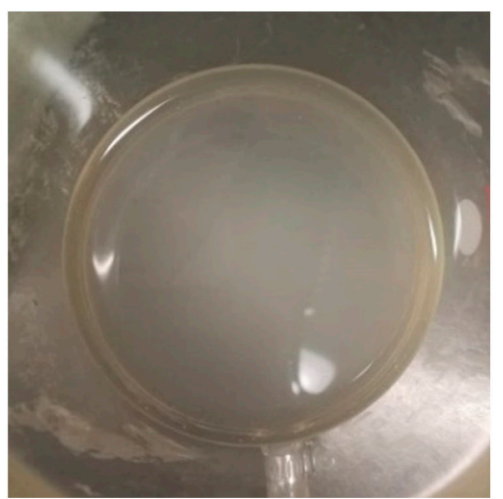

(d)

Figure 9. (a) Intrinsic dissolution profiles of Lor, Lor-Oxa CAB, and Lor-Oxa hydrate, (b) intrinsic dissolution profiles of Lor and Lor-Oxa hydrate, (c) PXRD pattern of Lor-Oxa CAB pellet after IDR study in comparison to those of Lor-Oxa CAB and Lor-Oxa hydrate, and (d) turbid dissolution medium after IDR experiment, suggesting bulk precipitation.

Table 2. Solubility at $25^{\circ} \mathrm{C}$ and intrinsic dissolution rate at $37^{\circ} \mathrm{C}$ of Lor, Lor-Oxa CAB, Lor-Oxa hydrate in $\mathrm{pH} 6.8$ phosphate buffer $(n=3)$.

\begin{tabular}{cccc}
\hline & Lor & Lor-Oxa CAB & Lor-Oxa Hydrate \\
\hline Solubility $\left(\mathbf{m g} \cdot \mathbf{L}^{-\mathbf{1}}\right)$ & $0.7 \pm 0.0$ & - & $1.15 \pm 0.04$ \\
IDR $\times \mathbf{1 0}^{\mathbf{4}}\left(\mu \mathrm{g} \cdot \mathbf{c m}^{-\mathbf{2}} \cdot \mathbf{s}^{-\mathbf{1}}\right)$ & $2.32 \pm 0.16$ & $220.1 \pm 4.8$ & $4.28 \pm 0.22$ \\
\hline
\end{tabular}




\subsection{Tabletability}

Tabletability is an important property of drugs for successful tablet formulation, especially when the drug loading is high [35]. Both Lor-Oxa CAB and Lor-Oxa hydrate crystals exhibited reduced tabletbility than Lor over the entire compaction pressure range of 25-350 MPa (Figure 10a). The tablet tensile strength of Lor-Oxa CAB increased with increasing pressure up to $200 \mathrm{MPa}$, beyond which higher pressure led to slightly lower tensile strength. A similar observation occurs for the Lor-Oxa hydrate, although the decline in tensile strength occurred at pressures higher than $100 \mathrm{MPa}$. At $350 \mathrm{MPa}$, intact tablets of Lor-Oxa hydrate could not be made due to extensive lamination of tablets (Figure S6). Such lamination suggests extensive elastic recovery during the decompression stage of the tableting cycle, which breaks bonding sites formed between particles during compression [36]. To understand their difference on tableting performance, compressibility and compactibility profiles are also compared (Figure 10b,c). At any given compaction pressure, the porosity of Lor tablets was always lower than those of the two new crystal forms, which were similar (Figure 10b). This suggests that the bonding area between Lor particles was larger than the two new multicomponent crystals, since the particle size and shape among them were similar (Figure S7). Interestingly, the apparent bonding strength, $\sigma_{0}$ (tablet tensile strength at 0 porosity), of Lor-Oxa hydrate is the highest, followed by Lor and Lor-Oxa $\mathrm{CAB}$ (Figure 10c). Therefore, the higher tabletabillity of Lor is attributed by the larger bonding area not higher bonding strength according to the bonding area - bonding strength interplay model of tablet tensile strength [37].

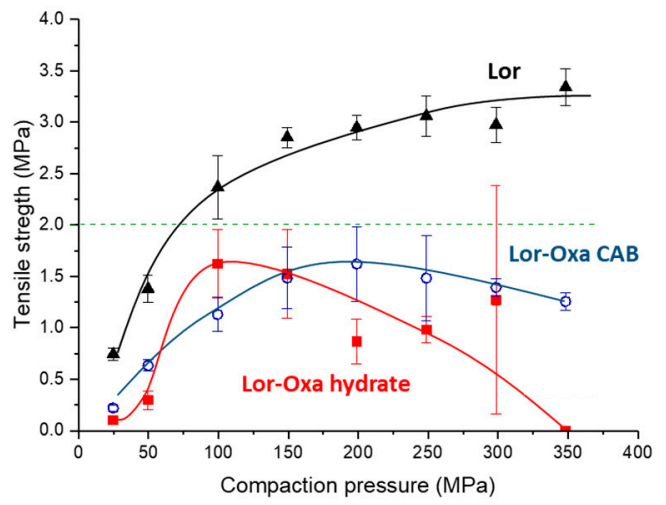

(a)

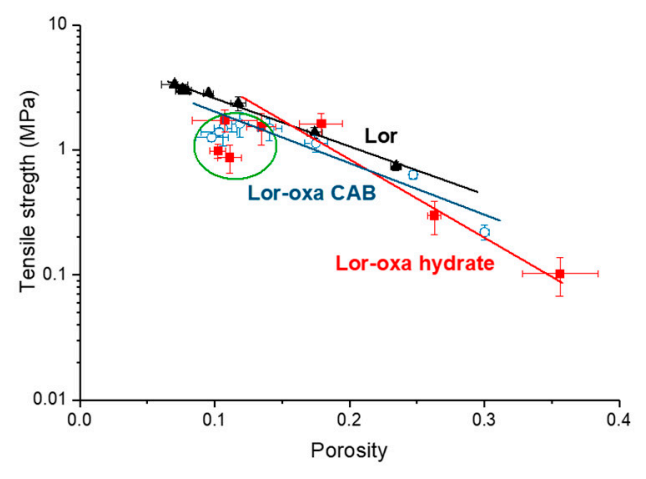

(c)

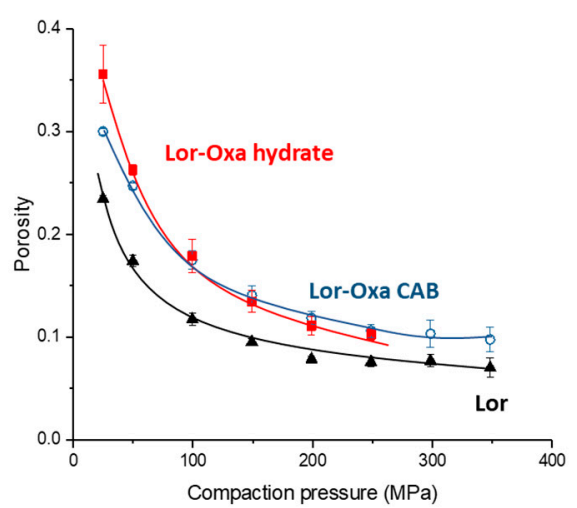

(b)

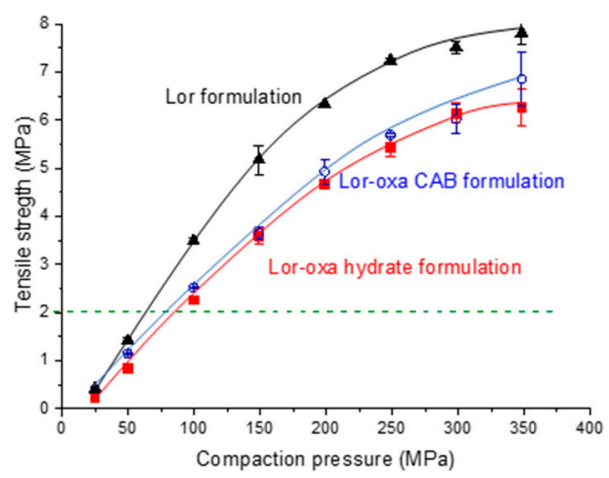

(d)

Figure 10. (a) Tabletability, (b) compressibility, and (c) compactibility profiles of pure Lor, Lor-Oxa CAB, and Lor-Oxa hydrate. (d) Tabletability profiles of formulations of Lor, Lor-Oxa CAB, and Lor-Oxa hydrate with $75 \%(w / w)$ MCC.

When mixed with $75 \%(w / w)$ MCC, all three solid forms of Lor exhibited good tabletability, following the descending order of Lor $>$ Lor-Oxa CAB $>$ Lor-Oxa hydrate (Figure 10d). 
Therefore, the different tabletabilities among the three crystal forms are directly translated to different tabletabilities of their formulations, i.e., no tabletability flipping occurred upon mixing with MCC [38]. This suggests that likely the BA remains the dominating factor in the BA-BS interplay [38]. All mixtures could form tablets with tensile strength of $2 \mathrm{MPa}$ at pressures below $100 \mathrm{MPa}$. Given the drug loading in the commercial Lor tablet products is around $2 \%$ because of the low dose of Lor $(10 \mathrm{mg})$, no issue with tablet mechanical strength is expected for any of the three crystal forms with a suitable formulation [39].

\section{Conclusions}

We have discovered and characterized two new multi-component crystalline forms of Lor with Oxa. Both crystal forms exhibit acceptable stability for drug development. Although both exhibit improved solubility and dissolution rate, Lor-Oxa CAB is much more soluble than Lor-Oxa hydrate. Therefore, Lor-Oxa CAB is the preferred crystal form for tablet formulation development although the Lor-Oxa hydrate is also suitable if desired. To develop a successful tablet formulation using Lor-Oxa $\mathrm{CAB}$, further studies to avoid its potential phase transition to Lor-Oxa hydrate during dissolution are needed to avoid unexpected dissolution failure.

Supplementary Materials: The following are available online at http://www.mdpi.com/2073-4352/10/11/996/s1, Figure S1: Standard curve of Lor in $\mathrm{pH}=6.8$ phosphate buffer; Figure S2: Effects of Oxa amount on solid phase identity during slurry experiments; Figure S3: PXRD patterns of Lor-Oxa hydrate powder at different times when stored at $100^{\circ} \mathrm{C}$; Figure S4: PXRD patterns of Lor-Oxa CAB and Lor-Oxa hydrate powders after solubility study in phosphate buffer; Figure S5: IDR profile of Lor-Oxa CAB in the first 16 min; Figure S6: Lamination of Lor-Oxa hydrate tablet compressed at 350 MPa; Figure S7: PLM images of Lor, Lor-Oxa CAB, and Lor-Oxa hydrate powders used for tablet compression; Video S1: HSM of Lor-Oxa CAB; Video S2: HSM of Lor-Oxa hydrate.

Author Contributions: Z.L. performed experiments, analyzed the data, and drafted the manuscript; H.C. solved crystal structures, wrote part of the draft; C.W. designed the experiments, performed experiments, and wrote a part of the draft; C.C.S. supervised the project, designed experiments, revised the manuscript, and acquired funding for this work. All authors have read and agreed to the published version of the manuscript.

Funding: This research received no external funding.

Acknowledgments: We thank the Minnesota Supercomputing Institute (MSI) at the University of Minnesota for providing the resources that contributed to the research results reported within this paper (http://www.msi. umn.edu). The Bruker-AXS D8 Venture diffractometer was purchased through a grant from NSF/MRI (\#1229400) and the University of Minnesota.

Conflicts of Interest: The authors declare no conflict of interest.

\section{References}

1. Vieth, M.; Siegel, M.G.; Higgs, R.E.; Watson, I.A.; Robertson, D.H.; Savin, K.A.; Durst, G.L.; Hipskind, P.A. Characteristic Physical Properties and Structural Fragments of Marketed Oral Drugs. J. Med. Chem. 2004, 47, 224-232. [CrossRef] [PubMed]

2. Williams, H.D.; Trevaskis, N.L.; Charman, S.A.; Shanker, R.M.; Charman, W.N.; Pouton, C.W.; Porter, C.J. Strategies to address low drug solubility in discovery and development. Pharm. Rev. 2013, 65, 315-499. [CrossRef] [PubMed]

3. Bučar, D.-K.; Filip, S.; Arhangelskis, M.; Lloyd, G.O.; Jones, W. Advantages of mechanochemical cocrystallisation in the solid-state chemistry of pigments: Colour-tuned fluorescein cocrystals. CrystEngComm 2013, 15, 6289-6291. [CrossRef]

4. Sun, C.C. Cocrystallization for successful drug delivery. Expert Opin. Drug Deliv. 2013, 10, $201-213$. [CrossRef] [PubMed]

5. Aitipamula, S.; Banerjee, R.; Bansal, A.K.; Biradha, K.; Cheney, M.L.; Choudhury, A.R.; Desiraju, G.R.; Dikundwar, A.G.; Dubey, R.; Duggirala, N.; et al. Polymorphs, Salts, and Cocrystals: What's in a Name? Cryst. Growth Des. 2012, 12, 2147-2152. [CrossRef]

6. Perumalla, S.R.; Sun, C.C. Improved solid-state stability of salts by cocrystallization between conjugate acid-base pairs. CrystEngComm 2013, 15, 5756-5759. [CrossRef]

7. Deng, J.-H.; Lu, T.-B.; Sun, C.C.; Chen, J.-M. Dapagliflozin-citric acid cocrystal showing better solid state properties than dapagliflozin. Eur. J. Pharm. Sci. 2017, 104, 255-261. [CrossRef] [PubMed] 
8. Wang, C.; Tong, Q.; Hou, X.; Hu, S.; Fang, J.; Sun, C.C. Enhancing bioavailability of dihydromyricetin through inhibiting precipitation of soluble cocrystals by a crystallization inhibitor. Cryst. Growth Des. 2016, 16, 5030-5039. [CrossRef]

9. Yamashita, H.; Sun, C.C. Improving dissolution rate of carbamazepine-glutaric acid cocrystal through solubilization by excess coformer. Pharm. Res. 2018, 35, 4. [CrossRef]

10. Sun, C.C.; Hou, H. Improving mechanical properties of caffeine and methyl gallate crystals by cocrystallization. Cryst. Growth Des. 2008, 8, 1575-1579. [CrossRef]

11. Yan, Y.; Chen, J.-M.; Lu, T.-B. Simultaneously enhancing the solubility and permeability of acyclovir by crystal engineering approach. CrystEngComm 2013, 15, 6457-6460. [CrossRef]

12. Wang, C.; Paul, S.; Sun, D.J.; Nilsson Lill, S.O.; Sun, C.C. Mitigating punch sticking propensity of celecoxib by cocrystallization-an integrated computational and experimental approach. Cryst. Growth Des. 2020, 20, 4217-4223. [CrossRef]

13. Chen, H.; Guo, Y.; Wang, C.; Dun, J.; Sun, C.C. Spherical Cocrystallization-An Enabling Technology for the Development of High Dose Direct Compression Tablets of Poorly Soluble Drugs. Cryst. Growth Des. 2019, 19, 2503-2510. [CrossRef]

14. Simons, F.E. Advances in H1-antihistamines. N. Engl. J. Med. 2004, 351, 2203-2217. [CrossRef]

15. Popović, G.; Čakar, M.; Agbaba, D. Acid-base equilibria and solubility of loratadine and desloratadine in water and micellar media. J. Pharm. Biomed. Anal. 2009, 49, 42-47. [CrossRef] [PubMed]

16. Khan MZ, I.; Raušl, D.; Zanoški, R.; Zidar, S.; Mikulčić, J.H.; Krizmanić, L.; Knežević, Z. Classification of Loratadine Based on the Biopharmaceutics Drug Classification Concept and Possible $\mathrm{i}$ in Vitro-in VivoCorrelation. Biol. Pharm. Bull. 2004, 27, 1630-1635. [CrossRef]

17. Sora, D.I.; Udrescu, S.; David, V.; Medvedovici, A. Validated ion pair liquid chromatography/fluorescence detection method for assessing the variability of the loratadine metabolism occurring in bioequivalence studies. Biomed. Chromatogr. 2007, 21, 1023-1029. [CrossRef]

18. Zhang, S.; Sun, M.; Zhao, Y.; Song, X.; He, Z.; Wang, J.; Sun, J. Molecular mechanism of polymer-assisting supersaturation of poorly water-soluble loratadine based on experimental observations and molecular dynamic simulations. Drug Deliv. Transl. Res. 2017, 7, 738-749. [CrossRef]

19. Kuminek, G.; Cavanagh, K.L.; da Piedade, M.F.M.; Rodríguez-Hornedo, N. Posaconazole Cocrystal with Superior Solubility and Dissolution Behavior. Cryst. Growth Des. 2019, 19, 6592-6602. [CrossRef]

20. Nacsa, A.; Ambrus, R.; Berkesi, O.; Szabo-Revesz, P.; Aigner, Z. Water-soluble loratadine inclusion complex: Analytical control of the preparation by microwave irradiation. J. Pharm. Biomed. Anal. 2008, 48, 1020-1023. [CrossRef]

21. Lin, S.-Y.; Hsu, C.-H.; Sheu, M.-T. Curve-fitting FTIR studies of loratadine/hydroxypropyl- $\beta$-cyclodextrin inclusion complex induced by co-grinding process. J. Pharm. Biomed. Anal. 2010, 53, 799-803. [CrossRef]

22. Frizon, F.; Eloy, J.d.O.; Donaduzzi, C.M.; Mitsui, M.L.; Marchetti, J.M. Dissolution rate enhancement of loratadine in polyvinylpyrrolidone K-30 solid dispersions by solvent methods. Powder Technol. 2013, 235, 532-539. [CrossRef]

23. Bandari, S.; Jadav, S.; Eedara, B.B.; Dhurke, R.; Jukanti, R. Enhancement of Solubility and Dissolution Rate of Loratadine with Gelucire 50/13. J. Pharm. Innov. 2014, 9, 141-149. [CrossRef]

24. Milak, S.; Medlicott, N.; Tucker, I.G. Solid lipid microparticles containing loratadine prepared using a Micromixer. J. Microencapsul. 2006, 23, 823-831. [CrossRef]

25. Üner, M.; Karaman, E.F.; Aydoğmuş, Z. Solid Lipid Nanoparticles and Nanostructured Lipid Carriers of Loratadine for Topical Application: Physicochemical Stability and Drug Penetration through Rat Skin. Trop. J. Pharm. Res. 2014, 13. [CrossRef]

26. Madhav, K.V.; Kishan, V. Self microemulsifying particles of loratadine for improved oral bioavailability: Preparation, characterization and in vivo evaluation. J. Pharm. Investig. 2018, 48, 497-508. [CrossRef]

27. Wang, J.; Chang, R.; Zhao, Y.; Zhang, J.; Zhang, T.; Fu, Q.; Chang, C.; Zeng, A. Coamorphous Loratadine-Citric Acid System with Enhanced Physical Stability and Bioavailability. Aaps Pharmscitech 2017, 18, 2541-2550. [CrossRef]

28. Alatas, F.; Aprilliana, M.; Gozali, D. The Preparation And Solubility Of Loratadine-Fumaric Acid Binary Mixture. Asian J. Pharm. Clin. Res. 2016, 10. [CrossRef]

29. Wang, C.; Perumalla, S.R.; Lu, R.; Fang, J.; Sun, C.C. Sweet Berberine. Cryst. Growth Des. 2016, 16, 933-939. [CrossRef] 
30. Wen, H.; Wang, C.; Sun, C.C. Fast Determination of Phase Stability of Hydrates Using Intrinsic Dissolution Rate Measurements. Cryst. Growth Des. 2019, 19, 5471-5476. [CrossRef]

31. Fell, J.T.; Newton, J.M. Determination of Tablet Strength by the Diametral-Compression Test. J. Pharm. Sci. 1970, 59, 688-691. [CrossRef]

32. Leane, M.; Pitt, K.; Reynolds, G. A proposal for a drug product Manufacturing Classification System (MCS) for oral solid dosage forms. Pharm. Dev. Technol. 2015, 20, 12-21. [CrossRef]

33. Wang, C.; Chopade, S.A.; Guo, Y.; Early, J.T.; Tang, B.; Wang, E.; Hillmyer, M.A.; Lodge, T.P.; Sun, C.C. Preparation, characterization, and formulation development of drug-drug protic ionic liquids of diphenhydramine with ibuprofen and naproxen. Mol. Pharm. 2018, 15, 4190-4201. [CrossRef] [PubMed]

34. Good, D.J.; Rodríguez-Hornedo, N.R. Solubility Advantage of Pharmaceutical Cocrystals. Cryst. Growth Des. 2009, 9, 2252-2264. [CrossRef]

35. Chen, H.; Aburub, A.; Sun, C.C. Direct Compression Tablet Containing 99\% Active Ingredient-A Tale of Spherical Crystallization. J. Pharm. Sci. 2019, 108, 1396-1400. [CrossRef]

36. Paul, S.; Sun, C.C. Gaining insight into tablet capping tendency from compaction simulation. Int. J. Pharm. 2017, 524, 111-120. [CrossRef]

37. Osei-Yeboah, F.; Chang, S.-Y.; Sun, C.C. A critical examination of the phenomenon of bonding area-bonding strength interplay in powder tableting. Pharm. Res. 2016, 33, 1126-1132. [CrossRef]

38. Paul, S.; Wang, C.; Sun, C.C. Tabletability Flip-Role of Bonding Area and Bonding Strength Interplay. J. Pharm. Sci. 2020. [CrossRef]

39. Sun, C.C.; Hou, H.; Gao, P.; Ma, C.; Medina, C.; Alvarez, F.J. Development of a high drug load tablet formulation based on assessment of powder manufacturability: Moving towards quality by design. J. Pharm. Sci. 2009, 98, 239-247. [CrossRef]

Publisher's Note: MDPI stays neutral with regard to jurisdictional claims in published maps and institutional affiliations. 